\title{
Dental malpractice cases in South Africa (2007-2016)
}

SADJ July 2019, Vol. 74 No. 6 p310 - p315

NL Makwakwa', PD Motloba²

\section{SUMMARY}

\section{Introduction}

Malpractice complaints against oral health professionals (OHPs) are increasing globally, and include breach of confidentiality, failure to obtain valid informed consent, issuing fraudulent medical certificates, claiming for services not rendered and violating regulations governing the dental profession.

South African dentists were most commonly charged with clinical complaints (59\%) whilst $29 \%$ of dental cases and $46 \%$ of dental therapist cases were for fraud.

Aims

To analyse the nature and outcome of malpractice by OHPs as reported by the Health Professions Council of South Africa (HPCSA)

\section{Methods}

A cross sectional descriptive survey of the data between 2007-2016.

\section{Results}

118 cases and 198 counts of dental malpractice were identified, predominantly by dentists $(74.6 \%)$, then specialists $(17 \%)$ and dental therapists (11\%). Males recorded $77.1 \%$ of complaints, Gauteng practitioners, $53.4 \%$, and $53.8 \%$ were OHPs who had worked for 10 years or more. Approximately a third (37\%) of the OHPs had more than one count of malpractice. Mean ages for independent practice were calculated.

Fraud, clinical misconduct and unprofessionalism constituted $66.7 \%, 23.2 \%$ and $10.1 \%$ of all counts of malpractice respectively, while there were significant differences between the involved dentists and dental therapists.

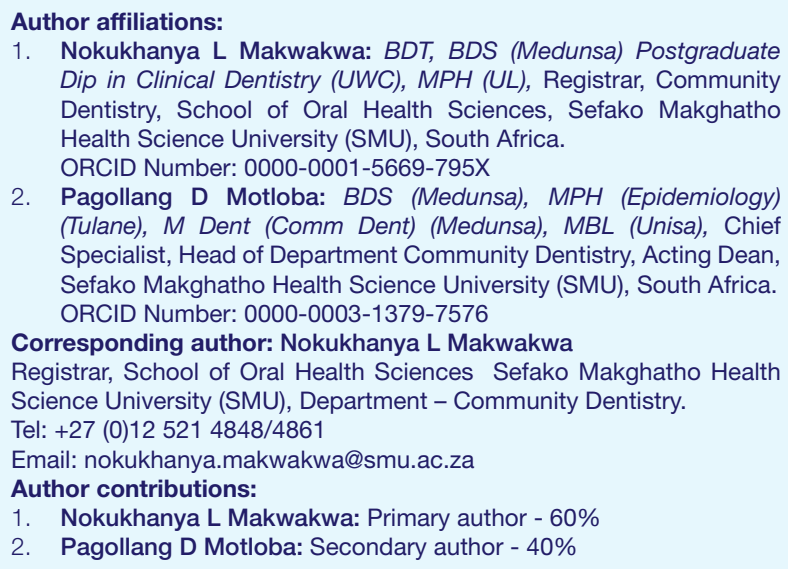

2. Pagollang D Motloba: BDS (Medunsa), MPH (Epidemiology) (Tulane), M Dent (Comm Dent) (Medunsa), MBL (Unisa), Chief Specialist, Head of Department Community Dentistry, Acting Dean, Sefako Makghatho Health Science University (SMU), South Africa. ORCID Number: 0000-0003-1379-7576

Corresponding author: Nokukhanya L Makwakwa

Registrar, School of Oral Health Sciences Sefako Makghatho Health

Science University (SMU), Department - Community Dentistry.

Tel: +27 (0)12 521 4848/4861

Email: nokukhanya.makwakwa@smu.ac.za

Author contributions:

1. Nokukhanya L Makwakwa: Primary author - $60 \%$

2. Pagollang D Motloba: Secondary author $-40 \%$

\author{
ACRONYMS \\ DOH: Dental Therapy and Oral Hygiene Board \\ MDB: $\quad$ Medical \& Dental Board \\ OHPs: Oral Health Professionals \\ PCC: Professional Conduct Committee
}

\section{Conclusion}

Fraud remains the most serious and ever increasing form of malpractice among Oral Health professionals.

\section{Keywords}

Dental malpractice, HPCSA, misconduct, oral health professional.

\section{INTRODUCTION}

Malpractice claims against Oral Health Professionals (OHPs) are on the increase worldwide. ${ }^{1-4}$ Malpractice encompasses breach of confidentiality, failure to obtain valid informed consent, issuing fraudulent medical certificates, claiming for services not rendered and violating regulations governing the dental profession. ${ }^{5}$

The major cause of malpractice is a failure to adhere to norms and standards of the profession, and a failure to achieve the desired therapeutic goals that are commonly accepted and rendered by peer practitioners. ${ }^{2}$

The literature records considerable variation in clinical malpractice claims lodged against OHPs. In the Netherlands, Turkey, Saudi Arabia, Spain and United States of America (USA), the clinical discipline most frequently implicated is oral surgery. ${ }^{3,4,6-8}$ In contrast, in Kerman province in Iran, the highest number of clinical complaints are in endodontics, followed by prosthodontics, operative dentistry and oral surgery. ${ }^{2}$ According to Postma, et al. ${ }^{9}$ a similar distribution of implicated clinical disciplines was recorded in South Africa (SA).

The study also showed that fraud was the leading form of malpractice laid against dental therapists (46\%), and accounted for $29 \%$ of malpractice claims laid against dentists. ${ }^{9}$ In most instances potential malpractice suits are settled between OHPs and the patients. In the absence of an amicable solution, patients normally report their complaints to the Health Professions Council of South Africa (HPCSA) or, rarely, lodge a civil malpractice suit. ${ }^{10}$

While anecdotal evidence points to a rising incidence of malpractice in SA, there has not been any scientific study in the past 10 years. Hence this project which sets 
out to investigate the nature, frequency and outcome of malpractice amongst OHPs as recorded by the Health Professions Council of South Africa (HPCSA).

The findings could inform curriculum changes, for example practice management and ethics modules. For the regulator, the findings will serve as evidence during engagement with health professionals.

\section{METHODOLOGY}

\section{Study design and sampling}

A retrospective cross sectional survey was undertaken on the records of claims of malpractice against Oral Health Professionals (OHPs) published by the Medical \& Dental Board (MDB), and the Dental Therapy \& Oral Hygiene Board (DOH) over the period, 2007-2016. These records included all malpractice cases finalised by the Professional Conduct Committee (PCC) of the HPCSA. ${ }^{11-13}$ No sampling and sample size determination were undertaken, as all available and complete records were included in this study.

\section{Ethics}

Ethical clearance to conduct this study was granted by The Sefako Makgatho Health Sciences University Research Ethics Committee (SMUREC) (SMUREC/302/2016: PG). Further approval was granted by the HPCSA to access data for this study. Anonymity and confidentiality was observed throughout.

\section{Data collection and data collection tool}

A specially designed data abstraction form was utilised to collect data on the (i) demographic profile of the oral health professional; (ii) academic and professional details, (iii) nature, frequency and outcome of malpractice. Data were sourced from HPCSA databases including registration records and finalised cases, for 2007 - 2016. The nature of malpractice was categorised as clinical and non-clinical, and these categories were recorded as indicated below.

\section{Clinical categories}

The clinical categories were classified according to the dental disciplines in which the offence occurred, namely: (i) Operative dentistry (ii) Maxillo facial and Oral Surgery - this included exodontia complications and failure of implants; (iii) Prosthodontics; (iv) Oral Medicine and Periodontology; (v) Orthodontics and (vi) not specified (no indication of the nature of clinical department).

\section{Non-clinical malpractice complaints}

Non-clinical malpractice complaints were categorized as fraud and unprofessionalism.

\section{(a) Fraud}

Fraud included all activities bearing monetary benefit to the OHPs such as claiming for services not rendered, employing an unregistered person(s) and practising out of the prescribed scope of practice.

\section{(b) Claiming for services not rendered}

Matters related to claiming for services not rendered included, split billing, over-charging, drafting misleading, inaccurate or incorrect statements to be submitted to Medical Aids. For example, (i) knowingly providing professional cosmetic procedures which are not covered by Medical Aids; (ii) fitting a gold filling and thereafter submitting a claim to the patient's Medical Aid Scheme as a direct restoration. Claiming for services not rendered also included the use of dental practitioner codes either by a dental therapist or by an unregistered person. The use of unlicensed radiographic machines was also included in this category.

\section{(c) Practicing out of the prescribed scope of practice}

Practising out of the prescribed scope included dental therapists and oral hygienists undertaking surgical, orthodontic and prosthodontic procedures, whilst for dentists the category included performing implant procedures without adequate training.

\section{(d) Unprofessionalism}

Unprofessionalism encompassed not acting according to the norms and standards as set out by the profession. Unprofessionalism included poor record keeping, failure to obtain informed consent, poor infection control measures, poor communication, lack of confidentiality, failure to honour patient appointments for follow up treatment, failing to ensure that the patient was attended by another practitioner in your absence, advertising in contravention to the HPCSA guidelines, being in Contempt of Council by failing and/ or neglecting to respond to Council correspondence and practising whilst not registered or suspended from the HPCSA register.

\section{Statistical analysis}

Descriptive and inferential statistical analyses were undertaken using SPSS version 24. Descriptive statistics determined the nature, frequency and outcome of malpractice, as well as enumerating the demographic profiles of the OHP's. Analysis of variance (ANOVA) and Student's $t$ test were used to compare the means between groups, as well as to compare the duration of independent practice before the offence was committed, in relation to the profession and gender and the nature of the malpractice. The association between the category of OHPs and the nature of malpractice committed was evaluated using the Chi-square test. The level of statistical significance was set at $p<0.05$.

\section{RESULTS}

The HPCSA received 26,958 complaints for processing during the study period. Excluded from the study were $47.3 \%(n=12758)$ of the total, constituting cases that did not include OHPs or where information was not forthcoming from the plaintiff. During this period $19 \%$ $(n=5434)$ of the complaints were referred to the ombudsman, $32 \%(n=8766)$ cases were finalised at the preliminary enquiry stage and $1 \%(n=248)$ were referred to the Professional Conduct Committee (PCC) which investigated matters concerning OHPs. 
Step I: Complaints are lodged by patients at the HPCSA by completing the relevant forms.

Step II: Administrators register complaints (incomplete cases referred back to the complainants).

Step III: Registered cases are either referred to the Ombudsman or preliminary enquiry for finalisation depending on their merit.

Step IV: Cases not finalised are referred to relevant Professional Conduct Committee (PCC) for finalisation (including sanctions).

Step V: All resolved cases are published as judgments on the HPCSA website.

Figure 1. Overview of HPCSA complaints process

Almost half (118/248) of these cases of dental malpractice were finalised and judgements published from 2006 to 2017 (Figure 1).

For the period 2007- 2016 the incidence of malpractice cases has remained almost constant. The PCC - MDB dental cases peaked from 2010 to 2014 whilst the PCC $\mathrm{DOH}$ cases showed a peak starting in 2011 and climaxing in 2014. Guilty verdicts handed down by the PPC - MDB dental showed three peaks namely in 2008, 2012 and 2014. On the other hand, the guilty verdicts delivered by PCC - DOH had a single peak in 2009 (Figure 2).

\section{Descriptive statistics of the participants}

The oral health practitioners charged by the HPCSA were predominantly dentists $76 \%$ (88/118), followed by dental specialists $14.4 \%(17 / 118)$ and then dental therapists $11 \%$ $(13 / 118)$. Majority practiced in Gauteng province, 53.4\% (63/118), were male, $77.1 \%$ (91/118), had graduated from Medunsa, (UL) 28.8\% (34/118), followed by the University of Pretoria 18.6\% (22/118) and the University of the Western Cape 21 (17.8\%). The majority of foreign qualified dentists 93\% (13/14) who had been implicated in malpractice were from universities in India.

The mean age at independent practice for dental therapists was 25.8 (SD: 4.9), for dentists 26.9 (SD: 3.9) and for dental specialists, 38.1 (SD: 5.8), these differences were significant at $p=0.000$. However, there were no significant differences in the ages of participants at the time of their first offense $(p=0.234)$ (Table 2).

Dental therapists entered independent practice comparatively older, but took a shorter time to commit an offence as compared with dentists and dental specialists.
Complaints registered $(n=26,958)$

Excluded $(n=12,758)$

- incomplete.

- cases not including OHPs.

Complaints referred $(n=14,200)$

inalised preliminary enquiry $(n=8,766)$ - Cases not finalised referred to...

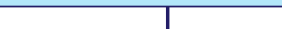

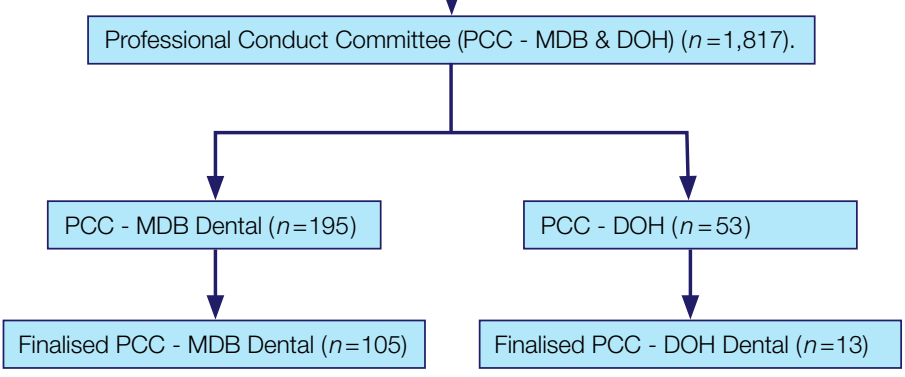

Malpractice

The majority of dentists $69.3 \%(61 / 88)$ and dental specialists, $94.1 \%(16 / 17)$ had one count of malpractice, in comparison with $69.2 \%(9 / 13)$ of the dental therapists who faced two or more counts. These differences were significantly different $(p=0.002)$.

\section{Nature and frequency of malpractice}

Non-clinical misconduct by OHPs accounted for $77.8 \%$ (154/198) of the counts, with fraud and unprofessionalism respectively registering $66.7 \%$, and $11.1 \%$ of all counts of malpractice. The nature of malpractice between dentists and dental therapists was statistically different $(p=0.000)$ (Table 3).
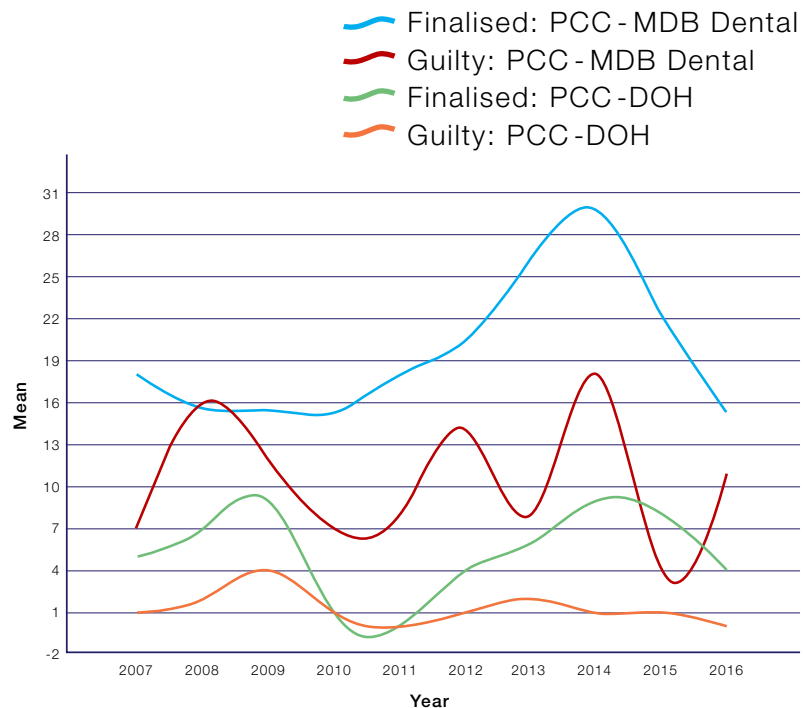

Figure 2. Cases finalised by type and dental professional board. 


\begin{tabular}{|c|c|c|c|c|c|c|c|c|c|}
\hline \multirow{2}{*}{\multicolumn{2}{|c|}{ Variable }} & \multicolumn{6}{|c|}{ Profession (\%) } & \multicolumn{2}{|c|}{ ANOVA } \\
\hline & & \multicolumn{2}{|c|}{ Dental therapist } & \multicolumn{2}{|c|}{ Dentists } & \multicolumn{2}{|c|}{ Dental specialists } & $\mathbf{F}$ & $P$ value \\
\hline \multirow{3}{*}{$\begin{array}{l}\text { Age: } \\
\text { Independent } \\
\text { practice }\end{array}$} & Mean (SD) & 25.8 & $(4.9)$ & 26.9 & (3.9) & 38.1 & $(5.8)$ & \multirow{3}{*}{50.459} & \multirow{3}{*}{0.000} \\
\hline & Minimum & 20.25 & - & 20.52 & - & 31.3 & - & & \\
\hline & Maximum & 34.57 & - & 45.47 & - & 55.8 & - & & \\
\hline \multirow{3}{*}{$\begin{array}{l}\text { Age: } \\
\text { First offence }\end{array}$} & Mean (SD) & 36.98 & $(9.2)$ & 41.13 & (11.94) & 44.36 & (9.9) & \multirow{3}{*}{1.473} & \multirow{3}{*}{0.234} \\
\hline & Minimum & 24.72 & - & 24.09 & - & 25.83 & - & & \\
\hline & Maximum & 52.29 & - & 72.41 & - & 61.47 & - & & \\
\hline
\end{tabular}

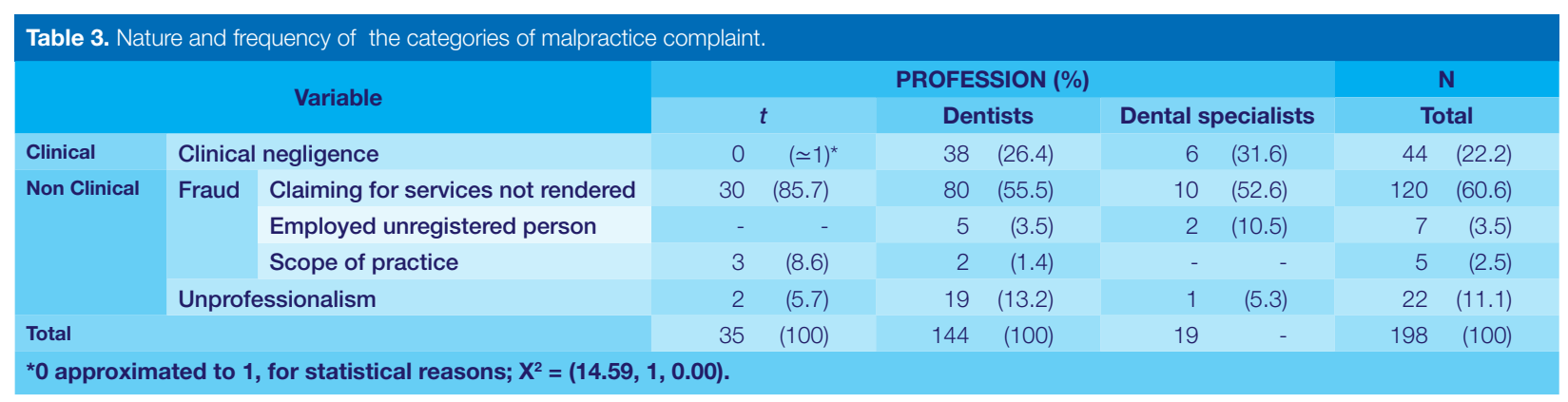

\section{Clinically related complaints}

The study shows that the majority $[72.7 \%(32 / 44)]$ of the clinically related complaints involved maxillofacial oral surgery $27.3 \%$ (12/44), followed by endodontic therapy and prosthodontics at $22.7 \%(10 / 44)$ each (Table 4).

\begin{tabular}{|l|r|r|}
\hline Table 4. Clinical negligence categories & & \\
\hline Clinical negligence categories & $\mathbf{N}$ & $(\%)$ \\
\hline Maxillo-facial oral surgery & 12 & $(27.3)$ \\
\hline Endodontics & 10 & $(22.7)$ \\
\hline Prosthodontics & 10 & $(22.7)$ \\
\hline Operative dentistry & 4 & $(9.1)$ \\
\hline Periodontics & 3 & $(6.8)$ \\
\hline Orthodontics & 2 & $(4.5)$ \\
\hline Not specified & 3 & $(6.8)$ \\
\hline Total & 44 & $(100)$ \\
\hline
\end{tabular}

The preponderant complaint in Maxillo-Facial Oral Surgery: was poor pre surgical planning resulting in implants being placed in the incorrect position thereby compromising the final prosthodontic rehabilitation of the patient. For example, implants which should be placed on the alveolar ridge were positioned too high up under the lip in the gingival tissue, which is not appropriate for the necessary mechanical and biological seals. Following these complications, dentists also failed to adequately manage and to appropriately refer these patients.

Complications that arose during exodontia procedures included poor management of ankylosed teeth, broken or fractures roots, lingual nerve damage and oro-antral opening.

Endodontic therapy complaints referred mainly to the following transgressions: Failure to diagnose root perforation during the performance of a root canal treatment on the patient; failure to diagnose surgical emphysema, using unknown mixtures in a tooth as root canal medicament, failure to take post-operative radiographs and omitting to inform the patient of a fractured endodontic file.
Prosthodontic failure referred mainly to: poor clinical planning and execution of prosthodontic treatment such as delivering poorly fitting dentures of poor quality and/ or workmanship, failure to achieve proper occlusion, and constructing an over-denture resulting in the loss of vitality of teeth and/or abscess.

Operative Dentistry complaints related to: poor clinical judgement when performing restorative procedures, e.g. not checking occlusion, incorrect bites.

Oral Medicine and Periodontology complaints referred to: failed surgical procedures such as gingivectomy not meeting the aesthetic needs of the patient.

Orthodontic complaints referred to: refusal to remove patient's orthodontic appliance.

Unspecified clinical complaints included: Failure to provide emergency treatment to the patient, performing complex operations which the practitioner was not sufficiently skilled to undertake and/or neglecting to refer the patient to a specialist.

\section{Duration before committing offence}

The mean time elapsed after commencing practice before a first offence was committed varied from 14.58 years (SD11.36) for dentists, 9.01 years (SD 7.4) for dental specialists to 11.22 years (SD 7.49) for dental therapists. There were no significance differences in these time periods $(p=0.113)$. However, there was a significance difference between the duration of times for the genders $(p=0.030)$ (Table 5).

\section{Outcome of malpractice disciplinary hearing}

Only four $(3.4 \% ; 4 / 118)$ practitioners were acquitted of malpractice. One case was closed due to the OHP being medically incapacitated. Penalties meted out to guilty practitioners included fines $49.2 \%$ (58/118), suspension $28.8 \%$ (34/118), caution $8.5 \%(10 / 118)$ or a combination of the penalties $13.6 \%(16 / 118)$. The PPC 


\begin{tabular}{|c|c|c|c|c|c|c|}
\hline & & \multirow[b]{2}{*}{ N (109)* } & & & \multicolumn{2}{|c|}{ ANOVA/T test } \\
\hline & & & \multicolumn{2}{|c|}{ Mean (SD) } & $\mathbf{F}$ & P-value \\
\hline \multirow[t]{3}{*}{ Profession } & Dental therapists & 12 & 11.20 & (8.22) & \multirow{3}{*}{2.22} & \multirow{3}{*}{0.113} \\
\hline & Dentists & 80 & 14.58 & (11.36) & & \\
\hline & Dental specialist & 17 & 9.01 & (7.49) & & \\
\hline \multirow[t]{3}{*}{ Nature of malpractice } & Clinical & 43 & 13.23 & (11.18) & \multirow{3}{*}{1.18} & \multirow{3}{*}{0.312} \\
\hline & Fraud & 57 & 12.6 & (9.94) & & \\
\hline & Unprofessionalism & 9 & 18.47 & (12.64) & & \\
\hline \multirow[t]{2}{*}{ Gender } & Female & 25 & 9.3 & $(5.5)$ & \multirow{2}{*}{4.83} & \multirow{2}{*}{$0.030^{*} \ddagger$} \\
\hline & Male & 84 & 14.55 & (11.55) & & \\
\hline
\end{tabular}

also recommended the following: (i) attendance at a post graduate fixed prosthodontic course for one OHP and (ii) attendance at a course in Ethics for two OHPs. The duration of suspension ranged from 30 months to five years, with a significant majority (68.2\%), suspended for a year or more. The fines imposed ranged between R1,000 and R125,000 (mean of R 13,147.06).

\section{DISCUSSION}

The discussion provides an overview of the nature, frequency and outcome of malpractice claims by patients (as processed by the HPCSA) against OHPs.

\section{Non-clinical malpractice}

This study indicates a gradual rise in reported cases of malpractice against OHP, which confirms a reported global phenomenon. ${ }^{1-4}$ The study revealed that non-clinical malpractice accounts for $77.8 \%$ of all reported cases, of which fraud was $66.7 \%$ and unprofessionalism, $11.1 \%$.

Compared with findings by Postma et al., cases of fraud, at $32.5 \%$, have more than doubled from 2007 to $2016 .^{9}$ Similarly, clinical misconduct by OHPs are on the rise globally. ${ }^{1-4,9,10,14-16}$

The apparent spate of malpractice in South Africa may be attributed in part to a greater tendency of patients to report incidents as they become more empowered and knowledgeable. Other reasons for the increase could be attributed to (i) the reduction in dental benefits by third party funders; (ii) closing down or consolidation of medical schemes; (iii) increasing operational costs of running a dental practice and (iv) competition in a shrinking market. ${ }^{17,18}$

Consistent with most global studies, ,2,8,10,14 but contrary to the Israeli study, ${ }^{15}$ middle aged males were most likely to engage in malpractice. Similarly, a majority of practitioners in metropolitan cities of Gauteng province were implicated. The high costs of living in metros fuels competition for scarce resources among OHPs.

This phenomenon is likely to encourage fraud and other forms of malpractice. These pressures are most observable among the males and middle aged OHPs. It was further observed that dental therapists committed exclusively non-clinical malpractice. This could be attributed to their limited scope of practice, and inexplicably low tariffs set for dentistry by medical insurance schemes.

\section{Clinical malpractice}

Clinical malpractice accounted for $22.2 \%$ of all counts of misconduct, involving, in a majority of cases, maxillofacial oral surgery $27.3 \%$ (12/44), endodontic therapy 22.7 (10/44) and prosthodontics 22.7 (10/44). This finding is consistent with data from the USA, Netherlands and Saudi Arabia. ${ }^{3,4,6-8}$ but contrary to that from Iran. ${ }^{10}$

The implicated clinical disciplines are characterised as being complex and highly technical, thereby requiring extensive clinical time and clinical skills. ${ }^{7}$ It is hence plausible to expect complications when these procedures are undertaken.

\section{Outcome and penalty of the malpractice}

Very few practitioners $(3.4 \% ; 4 / 118)$ were acquitted of malpractice by the HPCSA. The low rates of exoneration indicate the robustness of the internal processes at the preliminary stages.

This process ensures that only serious cases meriting full investigation are referred to the practice conduct committees (PCC - MDB and PCC - DOH).

The HPCSA suspended $28.8 \%$ (34), OHPs for varying duration of times, compared with small numbers in Iran $(0.2 \%) .{ }^{10}$ This disparity in suspension rates is attributed to the nature of misconduct committed.

South African OHPs engage in fraud, which is regarded as serious, unethical and unprofesional, while Iranian practitioners tend to commit clinical misconduct that is not prosecutable if it is judged not negligent.

The results indicate extreme variation in the fines imposed on OHPs. The mean amount payable to the HPCSA was R13 147.06, with fines ranging between $\mathrm{R} 1000$ and R125 000.

This is consistent with the literature, which recorded a mean payment of $\$ 2230$ and a maximum of $\$ 13,000^{10}$; and between $€ 18,001$ and $€ 240,000$. $^{19}$ The variation can be attributed to the nature and severity of the offences.

\section{CONCLUSIONS}

Non-clinical malpractice is on the increase and this is reflective of the volatile environment under which OHP's are practising in South Africa. 


\section{Recommendation}

This study finding should be interpreted with caution, as there are some design limitations. For example, this was a cross-sectional study, therefore causality cannot be inferred.

The research was conducted on a small sample size and therefore, the results cannot be generalised either with regard to the Tshwane Metropolitan as a whole or to other areas. The study should have involved more participants both at different levels and in Tshwane Metropolitan as well as other locations.

Despite limitations, the current study provided useful information that may inform the design of further studies.

\section{Recommendations}

There should be strong emphasis on ethics and practice management in order to capacitate OHP's to adhere to the Professional Code of Conduct. Relevant curricula and CPD courses must be developed to achieve this outcome.

To mitigate complication associated with complex procedures, it is imperative for OHPs to upskill, to invest in new technologies and to respect the patient's wishes and expectations. It is further recommended that an in-depth study be undertaken to explore factors that contribute to the increase in malpractice.

\section{References}

1. Mellor A, Milgrom P. Prevalence of complaints by patients against general dental practitioners in greater Manchester. BDJ 1995; 178(7):249.

2. Hashemipour MA, Pour FM, Lotfi S, Nassab AHG, Rahro MD, Mehrak M. Evaluation of dental malpractice cases in Kerman province (2000-2011). J Forensic Leg Med. 2013; 20(7):933-8.

3. Al-Ammar W, Guile EE. A one-year survey of dental malpractice claims in Riyadh. Saudi Dent J. 2000; 12(2):95-9.

4. Milgrom P, Fiset L, Whitney C, Conrad D, Cullen T, O'Hara D. Malpractice claims during 1988-1992: a national survey of dentists. JADA. 1994; 125(4):462-9.

5. Health Professions Council of South Africa (HPCSA). Guidelines for good practice in the health care professions. Accessed May 2017. URL: http://www.hpcsa.co.za/Uploads/editor/UserFiles/downloads/conduct_ethics/rules/ generic_ethical_rules/booklet_2_generic_ethical_rules_ with_anexures.pdf.

6. Vermaire J, Eijkman M. Complaints against dentists. Ned. Tijdschr. Tandheelkd. 2001; 108(1):11-5.

7. Ozdemir MH, Saracoglu A, Ozdemir AU, Ergonen AT. Dental malpractice cases in Turkey during 1991-2000. J Forensic Leg Med. 2005; 12(3): 137- 42.

8. Perea-Pérez B, Labajo-González E, Santiago-Sáez A, Albarrán-Juan E, Villa-Vigil A. Analysis of 415 adverse events in dental practice in Spain from 2000 to 2010. Med Oral Patol Oral Cir Bucal. 2014; 19(5): e500.

9. Postma TC, Van Wyk PJ, Heymans J, White JG, Prinsloo P. An analysis of complaints against oral health professionals charged with misconduct at the HPCSA: 2004-2009: SADJ. 2011; 66(9):420 - 5 .

10. Kiani M, Sheikhazadi A. A five-year survey for dental malpractice claims in Tehran, Iran. J Forensic Leg Med. 2009; 16(2):76-82.
11. Health Professions Council of South Africa (HPCSA). Historical judgements. Accessed May 2017. URL: https:// www.hpcsa.co.za/Recent Convictions/Historical.

12. Health Professions Council of South Africa (HPCSA). HPCSA Register. Accessed May 2017. URL: http://isystems.hpcsa.co.za/iregister/.

13. Health Professions Council of South Africa (HPCSA). HPCSA Annual Reports. Accessed May 2017. URL: https://www.hpcsa.co.za/Publications/Reports.

14. Cheah C, Soon H, Ngeow W, Monerasinghe E, Lian C. Patients complaints of dental malpractice in Malaysia Part II: Analysis of cases from 1997-2004. Dent J Malays. 2005; 26(2).

15. Givol N, Frenkel T, Tickotsky N, Moskovitz M. The incidence and nature of complaints against dentists for the treatment of children in Israel from 1992-2011. Community Dent Health 2015; 32(1): 56-9.

16. Manca R, Bruti V, Napoletano S, Marinelli E. A 15 years survey for dental malpractice claims in Rome, Italy. J Forensic Leg Med. 2018; 58:74-7.

17. Snyman L, van der Berg-Cloete SE, White JG. The perceptions of South African dentists on strategic management to ensure a viable dental practice. SADJ. 2016; $71(1): 12-8$

18. Erasmus D, Ranchod S, Abraham M, et al. Challenges and opportunities for health finance in South Africa: a supply and regulatory perspective. Johannesburg: FinMark Trust 2016.

19. Perea-Pérez B, Santiago-Sáez A, Labajo-González M-E, Albarrán-Juan ME. Professional liability in oral surgery: legal and medical study of 63 court sentences. Med Oral Patol Oral Cir Bucal. 2011; 16(4):e526-31. 